\title{
Effects of long- and short-term darbepoetin-a treatment on oxidative stress, inflammation and endothelial injury in ApoE knockout mice
}

\author{
Evrim Dursun Özdemir ${ }^{1}, A-D$, Aysegul Hanikoglu ${ }^{1, D}$, Aysegul Cort ${ }^{2}, B, D, F$, Beste Ozben ${ }^{3, A, B}$, Gultekin Suleymanlar ${ }^{4, A}, B$, Tomris Ozben ${ }^{1, A, C, E}$ \\ 1 Department of Biochemistry, Faculty of Medicine, Akdeniz University, Antalya, Turkey \\ ${ }^{2}$ Department of Nutrition and Dietetics, Faculty of Health Sciences, Sanko University, Gaziantep, Turkey \\ ${ }^{3}$ Department of Cardiology, Faculty of Medicine, Marmara University, Istanbul, Turkey \\ ${ }^{4}$ Department of Nephrology, Faculty of Medicine, Akdeniz University, Antalya, Turkey \\ A - research concept and design; $\mathrm{B}$ - collection and/or assembly of data; $\mathrm{C}$ - data analysis and interpretation; \\ $D$ - writing the article; $E$ - critical revision of the article; $F$ - final approval of article
}

\section{Address for correspondence}

Tomris Ozben

E-mail: ozben@akdeniz.edu.tr

\section{Funding sources}

This study was supported by Akdeniz University Research Funds(Project Number 2006.03.0122.004)

\section{Conflict of interest}

None declared

Received on November 25, 2015

Revised on December 27, 2015

Accepted on April 25, 2016

\begin{abstract}
Background. Atherosclerosis and atherosclerosis-related complications are the main cause of death in the world. Vascular injury in response to inflammation and enhanced oxidant stress promotes endothelial dysfunction and leads to atherosclerotic lesions.

Objectives. Low-dose treatment with darbepoetin-a may be a potential therapeutic tool for endothelial injury and atherosclerosis.

Material and methods. In order to study the effect of darbepoetin-a on endothelial injury and atherosclerosis, we used $\mathrm{Apo} \mathrm{E}^{-1}$ mice as the atherosclerotic mice model. We monitored atherosclerosis and plaque formation histochemically in ApoE knockout mice at early and late stages of atherosclerosis. Darbepoetin-a was injected intraperitoneally at a dose of $0.1 \mu \mathrm{g} / \mathrm{kg}$ to $\mathrm{ApoE}^{-1-}$ mice. The results of $2 \mathrm{Apo}^{-1-}$ mice groups injected with darbepoetin-a (early and late stages of atherosclerosis) were compared to the results of the corresponding saline injected ApoE--- mice groups and the control (C57BL/6) mice.

Results. Lipid profile (total cholesterol, triglyceride), inflammation (CRP, IL-6, histamine), endothelial injury (ICAM-1, selectin) and oxidative stress markers (lipid peroxidation, protein oxidation) were significantly increased in 4 atherosclerotic groups compared to the control group. Short-term darbepoetin-a had no marked effects on indicators of inflammation and endothelial injury in the ApoE knockout mice groups compared to the ApoE knockout mice not treated with darbepoetin-a, however, darbepoetin-a significantly decreased 8-isoprostane and protein carbonyl content. Long term darbepoetin-a treatment reduced oxidative stress in $\mathrm{ApoE}^{-1-}$ mice.
\end{abstract}

Conclusions. This study contributes to understanding and elucidating the biochemical changes occurring during early and late stages of atherosclerosis development regarding lipid profile, inflammation, endothelial injury and oxidative stress markers.

Key words: oxidative stress, atherosclerosis, endothelial dysfunction, darbepoetin-a, ApoE knockout mice

DOI

10.17219/acem/62834

\section{Copyright}

Copyright by Author(s)

This is an article distributed under the terms of the

Creative Commons Attribution Non-Commercial License

(http://creativecommons.org/licenses/by-nc-nd/4.0/) 
The prevalence of cardiovascular diseases (CVD) rises with ageing, and atherosclerosis is the the major underlying cause of CVDs. Atherosclerosis affects large and medium-sized arterial vessels. Interactions of genetic and environmental factors play a major role in atherosclerosis development. Atherosclerosis is defined by vascular inflammation, endothelial dysfunction, accumulation of lipids, cholesterol and cellular debris within the intima of the artery wall. This accumulation results in vascular remodeling, blood flow abnormalities, plaque formation, luminal blockage and decreased distribution of oxygen to target tissues. ${ }^{1}$

The proposed initial step of atherogenesis is endothelial dysfunction inducing a number of compensatory responses and leading to the alteration of normal vascular homeostatic properties. ${ }^{2}$ Atherosclerotic lesions develop as a result of inflammatory stimuli, subsequent release of various cytokines, proliferation of smooth muscle cells, synthesis of connective tissue matrix and accumulation of macrophages and lipids. It is now recognized that inflammation plays a pivotal role in early atherogenesis. ${ }^{3}$

ApoE knockout $\left(\mathrm{ApoE}^{-/}\right)$mice are used most commonly for the study of in vivo experimental models for human atherosclerosis. ${ }^{4}$ The mouse is the major mammalian model organism for the discovery of genes and mechanisms related to atherosclerosis. Several candidate genes suspected of contributing to the progression of atherosclerosis have been tested through the development and analysis of gene deficient or transgenic mice. "The generation of ApoE knockout $\left(\mathrm{ApoE}^{-/-}\right)$mice has been one of the most critical advances in the elucidation of factors affecting atherogenesis". ${ }^{5,6}$ The ApoE knockout $\left(\mathrm{ApoE}^{-/}\right)$mice model is presently the most prevalent murine model in cardiovascular research and has given extensive insights into atherosclerosis. "These mice develop spontaneous atherosclerotic plaques with many features similar to human lesions and allow follow-up of atherosclerosis process from its earliest stages; moreover it can be used as an ideal model for biomarker discovery"7,8 ApoE ${ }^{-/-}$mice exhibit chronic hypercholesterolemia and develop early and spontaneous atherosclerotic lesions. ${ }^{9}$ Organic fluids like serum represent the most convenient samples because of their easy access, providing a means to explore possible markers for atherosclerosis and identify the most appropriate ones for clinical use. Furthermore, such biomarkers have the potential to provide information about different atherosclerosis stages and clinical help from a prognostic point of view.

Darbepoetin- $\alpha$ is a hyperglycosylated erythropoiesis stimulating protein that has an almost 3-fold longer mean terminal half-life than recombinant human erythropoietin, which allows for less frequent dosing. Darbepoetin- $\alpha$ has been defined as tissue protector in the kidney and preserves capillary network. Darbepoetin- $\alpha$ protects renal tissue against the adverse effects of ischaemia, provides well-tolerated therapy for the treatment of chemotherapy-induced anemia and reduces lipopolysac- charide-induced hepatocellular apoptosis. ${ }^{10-12}$ Darbepoetin- $\alpha$ reduces infarcted myocardium size, weakens cardiomyocyte apoptosis and enhances cardiac function. ${ }^{13}$ The effects of darbepoetin- $\alpha$ on the biochemical parameters of atherosclerosis and histopathological lesions in apolipoprotein $\mathrm{E}$ knockout $\left(\mathrm{ApoE}^{-/-}\right)$mice are not known. In this study, we investigated the effects of darbepoetin- $\alpha$ treatment during atherosclerosis progression and development in ApoE knockout mice fed with a standard diet compared to wild-type C57BL/6 mice having the same genetic profile as the control group. Our aim was to reveal the possible differences in various biochemical parameters regarding lipid profile, inflammation, endothelial injury and oxidative stress in $\mathrm{ApoE}^{-/-}$and control mice groups and to understand the effect of darbepoetin- $\alpha$ on the studied parameters. Histological assessment of the atherosclerotic lesions was carried out in the sections obtained from the aortic arch (arcus aortae) and subjected to immunohistochemical staining from the $\mathrm{ApoE}^{-/-}$mice at 8, 12 and 20 weeks of age, to demonstrate overt signs of atherosclerotic changes, lipid formation and foam cells during atherosclerosis progression.

\section{Material and methods}

\section{Laboratory animals}

All experimental protocols conducted on mice were performed in mice were maintained in accordance with the Guide of the Animal Care and Use Committee of Akdeniz University and were used in accordance with an animal study proposal approved by the NIAID Animal Care and use Committee (NIH Publication no.86-23, revised 1996) and the "Principle of Laboratory Animal Care" (NIH publication no. 86-23, revised 1985). Genetically modified male homozygous $\mathrm{ApoE}^{-/-}$mice were obtained from Taconic Laboratories (Ejby, Denmark) and the control group having the same genetic background except for the ApoE gene (C57BL/6) were obtained from Akdeniz University, Experimental Animal Laboratory, Antalya, Turkey, at 3-4 weeks of age. ${ }^{14}$ The animals were kept under controlled $12 \mathrm{~h}$ light-dark cycles, $23 \pm 1^{\circ} \mathrm{C}$ constant temperature and $50 \pm 5 \%$ humidity conditions with free access to chow diet and water.

\section{Drug treatment}

The ApoE-'- mice were split into 4 groups (10 animals each) which were injected with darbepoetin- $\alpha$ or saline for a period of 8 or 20 weeks (initial and advanced stages of atherosclerosis, respectively). The darbepoetin- $\alpha$ (Aranesp, Amgen, Thousand Oaks, USA) was dissolved in saline and used in a dose of $0.1 \mathrm{mg} / \mathrm{kg} /$ week. The drug solution was freshly prepared on every injection day and administered to the mice intraperitoneally. ${ }^{15}$ The dose 
was adjusted according to the body weight of each mouse during the treatment period.

\section{Histological examination of the aorta}

For histological examinations to show initial, intermediate and advance atherosclerotic lesion, the ApoE knockout mice were sacrificed at the termination of 8,12 and 20 weeks of darbepoetin- $\alpha$ treatment. The hearts and aorta of the mice were carefully removed and dissected free from connective tissue from the brachiocephalic trunk to the iliac bifurcation point, washed with cold saline and fixed with $10 \%$ neutral buffered formalin, then processed for embedding in paraffin wax. ${ }^{14}$ For histological assessment of atherosclerosis, the samples were processed in accordance with the usual manner and embedded in paraffin and cut into $4 \mu \mathrm{m}$ sections. The tissue sections were stained with hematoxylin and eosin. Stained tissue sections were visualized using light microscopy (Leica).

\section{Blood sample collection}

Blood samples were collected from the abdominal aorta at the end of the $8^{\text {th }}$ and $20^{\text {th }}$ weeks of darbepoetin- $\alpha$ or saline treatment of the $\mathrm{ApoE}^{-/-}$mice and control mice (C57BL/6) under ether anesthesia, and centrifuged at $3000 \mathrm{rpm}$ for $10 \mathrm{~min}$. Each serum sample was separated and stored in aliquots at $-80^{\circ} \mathrm{C}$ with addition of a protease inhibitor cocktail (Catalog no. \#S8820, Sigma-Aldrich, St. Louis, USA) to avoid protein degradation during the preparation of the samples. ${ }^{16}$

\section{Biochemical analysis}

\section{Triglyceride assay}

Triglyceride levels were determined using the enzymatic colorimetric method of the Roche Diagnostics assay kit (Catalog no. \#11730711, Indianapolis, Indiana, USA) in the Roche Hitachi Modular P800-ISE autoanalyzer.

\section{Cholesterol assay}

Cholesterol levels were determined using the enzymatic colorimetric Roche Diagnostics assay kit (Catalog no. \#11491458, Indianapolis, USA) in the Roche Hitachi Modular P800-ISE autoanalyzer.

\section{Protein carbonyl colorimetric assay}

Protein-bound carbonyls were measured using a protein carbonyl assay kit (Catalog no. \#1005020, Cayman Chemical, Ann Arbor, USA). The utilized method was based on the covalent reaction of the carbonylated protein side chain with 2,4-dinitrophenylhydrazine (DNPH) and detection of the produced protein hydrazone at an absorbance of $370 \mathrm{~nm}$. The results were calculated using the extinction coefficient of $22 \mathrm{mM}^{-1} \mathrm{~cm}^{-1}$ for aliphatic hydrazones and expressed as $\mathrm{nmol} / \mathrm{mg}$ protein.

\section{8-isoprostane assay}

Serum 8-iso-prostaglandin F2a was measured using an enzyme immunoassay (EIA) kit (Catalog no. \#516351, Cayman Chemical, Ann Arbor, USA). The protocol of the kit is based on the competition between 8-isoprostane and 8-isoprostaneacetylcholinesterase conjugate (Tracer) for limited 8-isoprostane-specific rabbit anti-serum binding sites.

Interleukin-6 (IL-6) assay

A mouse IL-6 ELISA kit (Catalog no. \#550950, BD OptEIA, BD Biosciences, USA) was used for the quantitative detection of serum IL-6. An IL-6 coated plate specific for monoclonal antibody was utilized. Each IL-6 present in the serum binds to the immobilized antibody. Streptavidin horseradish peroxidise (HRP) conjugate was mixed with biotinylated anti-mouse IL- 6 antibody, producing an antibody-antigen-antibody "sandwich". The plate was washed and TMB solution was added, which produced color in direct proportion to the amount of IL-6 present in the original sample, and absorbances measured at $450 \mathrm{~nm}$.

\section{Histamine assay}

Histamine levels were determined using an assay kit (Catalog no. \#A05890, SPI BIO, Massy, France). This method depends on the competition between unmarked derivatized histamine and acetylcholinesterase linked to a histamine tracer for a limited number of mouse anti-histamine antibody sites.

\section{Mouse C-reactive protein (CRP) assay}

CRP levels were measured using an assay kit (Catalog no. \#41-CRPMS-E01, Alpco Diagnostics, Salem, USA). The CRP present in serum reacts with the anti-CRP antibodies coated to the surface of the wells. After washing, anti-CRP antibodies conjugated with horseradish peroxidase were added, forming complexes with the previously bound CRP. Enzyme bound to the immunosorbent was assayed by the addition of a chromogenic substrate. The bound enzyme quantity depends on the concentration of CRP in the serum.

\section{E-selectin assay}

E-selectin levels were evaluated with a quantitative sandwich enzyme immunoassay kit (Catalog no. \#MES00, R\&D Systems, Minneapolis, USA). A microplate was 
pre-coated with a monoclonal antibody specific to mouse E-selectin. An immobilized antibody was utilized for binding of any mouse E-selectin present in the serum. After the washing steps, E-selectin specific enzyme-linked monoclonal antibody was added to the wells. Following a wash, a substrate solution was added to the wells. The enzyme reaction yielded a blue product that turned yellow when the Stop Solution was added. The intensity of the color was proportional to the amount of mouse E-selectin bound in the first step. The minimum detectable dose of mouse E-selectin was $2.8-4.7 \mathrm{pg} / \mathrm{mL}$. The mean minimum detectable dose was $3.8 \mathrm{pg} / \mathrm{mL}$.

\section{ICAM-1 (CD54) ELISA assay}

Mouse sICAM-1 (CD54) levels in the serum were determined using the Thermo Scientific ${ }^{\mathrm{TM}}$ Mouse-Soluble ICAM-1 (CD54) ELISA Assay kit (Catalog no. \#633215, Pierce Biotechnology, USA). The procedure was performed according to the instructions of the manufacturer. The asssay range was $25.6-1000 \mathrm{ng} / \mathrm{mL}$.

\section{Statistical analysis}

Statistical analyses were carried out using SPSS packed program v. 17 (IBM, Chicago, USA). Data was expressed as mean \pm standard deviation (SD). Normal distribution and differences between variances were determined using Kolmogorov-Smirnov and Levene tests, respectively. For comparisons between the 2 groups, the Student's t-test and Mann-Whitney U-test were used as appropriate. For subgroup analyses, the Kruskal-Wallis test was used to determine significant differences. The MannWhitney U-test was used to determine differences between the groups if a significant difference was found in the Kruskal-Wallis test. P-value $<0.05$ was considered statistically significant.

\section{Results}

\section{Animal data}

At the end of the study, the body weights were not significantly different among the groups. We did not observe any differences in animal behavior or activity in $\mathrm{ApoE}^{-/-}$mice compared to the controls.

\section{Histopathological findings}

Atherosclerotic lesions of the aortic arch are shown for the control (C57BL/6) mice (Fig. 1a), 8-week-old ApoE-/mice (Fig. 1b), 12-week-old ApoE ${ }^{-/-}$mice (Fig. 1c) and twenty-week-old ApoE ${ }^{-/-}$mice (Fig. 1d). The ApoE ${ }^{-/-}$mice developed early atherosclerotic lesions in the aortic root, characterized by accumulation of foam cells in the sub- endothelial space, formation of a lipid core, thickening of the intima-media and narrowing of the lumen. ${ }^{14}$ Changes in the histopathological grade of atherosclerosis was significantly different among the groups. No atherosclerotic lesions were observed in the control mice. The median value of the aorta lumen was highest in the aorta of the control mice and lowest in the 20 week-old ApoE - $^{-1}$ mice. The first atherosclerotic lesions were developed and characterized in the 8-week-old $\mathrm{ApoE}^{-/-}$mice group. Lipid laden macrophage formation was observed in the 12-week-old ApoE - $^{-/}$mice group. Extracellular lipid formation and foam cells were seen in the 20-week-old $\mathrm{ApoE}^{-/-}$mice.

\section{Biochemical analyses}

\section{Triglyceride levels}

Triglyceride levels in the darbepoetin- $\alpha$-treated and non-treated atherosclerotic $\mathrm{ApoE}^{-1-}$ mice groups at the initial and advanced stages of atherosclerosis were significantly increased compared to the control (C57BL/6) group ( $\mathrm{p}<0.001$ ) (Fig. 2). Darbepoetin- $\alpha$ treatment caused a significant increase in triglyceride levels compared to the non-treated ApoE knockout mice group at the initial atherosclerotic stage $(\mathrm{p}<0.05)$. In contrast, triglyceride levels were not significantly affected by the darbepoetin- $\alpha$ treatment in the advanced stage groups. The triglyceride levels of the darbepoetin- $\alpha$-treated and non-treated ApoE knockout mice groups at the advanced atherosclerotic stage were significantly higher compared to the darbepoetin- $\alpha$-treated and non-treated ApoE knockout mice groups at the initial atherosclerotic stage $(\mathrm{p}<0.05)$.

\section{Cholesterol level}

Serum cholesterol levels of the darbepoetin- $\alpha$-treated, and non-treated ApoE knockout mice groups at the initial and advanced stages of atherosclerosis were significantly increased compared to the C57BL/6 mice ( $\mathrm{p}<0.001$ ), as shown in Fig. 3. Cholesterol levels were not significantly affected by darbepoetin- $\alpha$ treatment in ApoE knockout mice groups at the initial and advanced atherosclerotic stages $(p>0.05)$. Darbepoetin- $\alpha$-treated, and non-treated ApoE ${ }^{-1-}$ mice groups at the advanced stage had significantly higher cholesterol levels compared to the darbepoetin- $\alpha$-treated, and non-treated ApoE knockout mice groups at the initial stage $(\mathrm{p}<0.05)$.

\section{Protein carbonyl levels}

Protein carbonyl levels were markedly higher in the $4 \mathrm{ApoE}^{-1-}$ mice groups compared to the C57BL/6 mice group ( $\mathrm{p}<0.001$ ), as shown in Fig. 4 . Darbepoetin- $\alpha$ treatment decreased the protein carbonyl level in the $\mathrm{ApoE}^{-/-}$ 
Fig. 1. A cross section of the aortic arch from control (C57BL/6) and ApoE-/- mice representing atherosclerosis progression. (a) The histological appearance of the aortic root of the control (C57BL/6) mice (b) 8-week-old ApoE-/- mice group (c) 12-week-old ApoE-/- mice group (d) 20-week-old ApoE-/- mice group

a

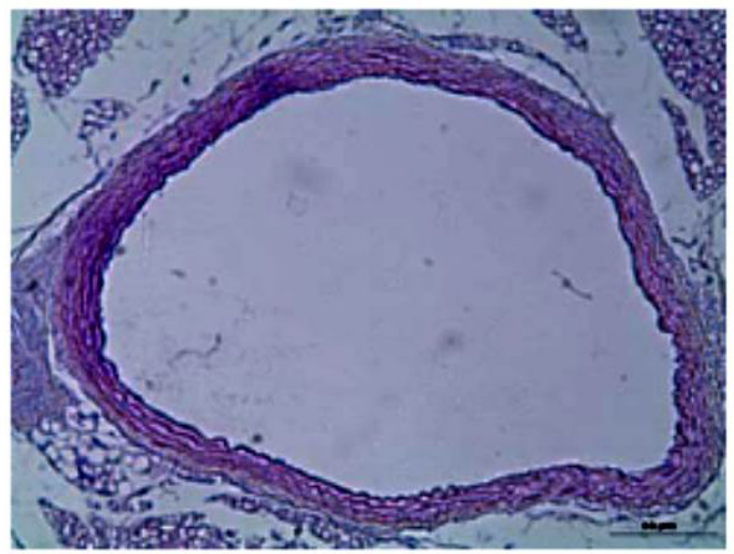

C

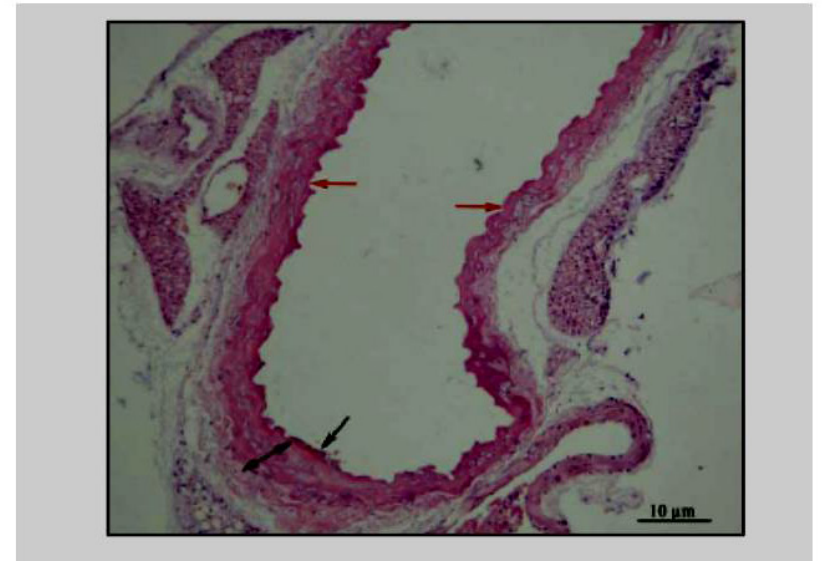

mice groups at both the initial and advanced atherosclerotic stages, but this diminution was significant only in the $\mathrm{ApoE}^{-1-}$ mice group at the advanced atherosclerotic stage $(\mathrm{p}<0.05)$.

\section{8-isoprostane level}

8-Isoprostane levels were significantly higher in $4 \mathrm{ApoE}^{-1-}$ mice groups compared to the $\mathrm{C} 57 \mathrm{BL} / 6$ mice group $(\mathrm{p}<0.001)$, as shown in Fig. 5. Darbepoetin- $\alpha$ treatment significantly decreased 8-Isoprostane levels in the $\mathrm{ApoE}^{-1-}$ mice groups at the initial and advanced atherosclerotic stages compared to the corresponding non-treated $\mathrm{ApoE}^{-1-}$ mice groups at the initial and advanced atherosclerotic stages ( $\mathrm{p}<0.01$ and $\mathrm{p}<0.05$ respectively).

\section{Interleukin-6 (IL-6) level}

IL-6 levels were significantly enhanced in $4 \mathrm{ApoE}^{-1-}$ mice groups compared to the C57BL/6 mice group $(\mathrm{p}<0.001)$, as shown in Fig. 6. The highest level was found in the non-treated $\mathrm{ApoE}^{-1-}$ mice group at the advanced atherosclerotic stage. There was no marked difference b

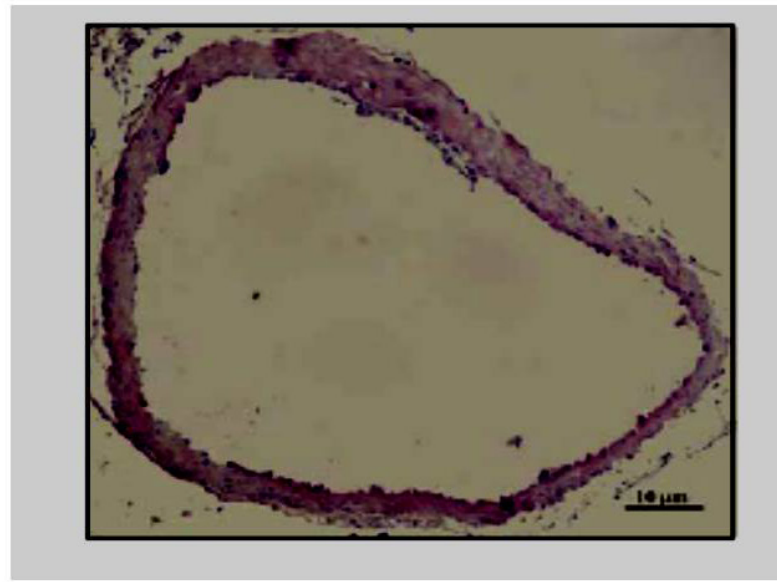

d

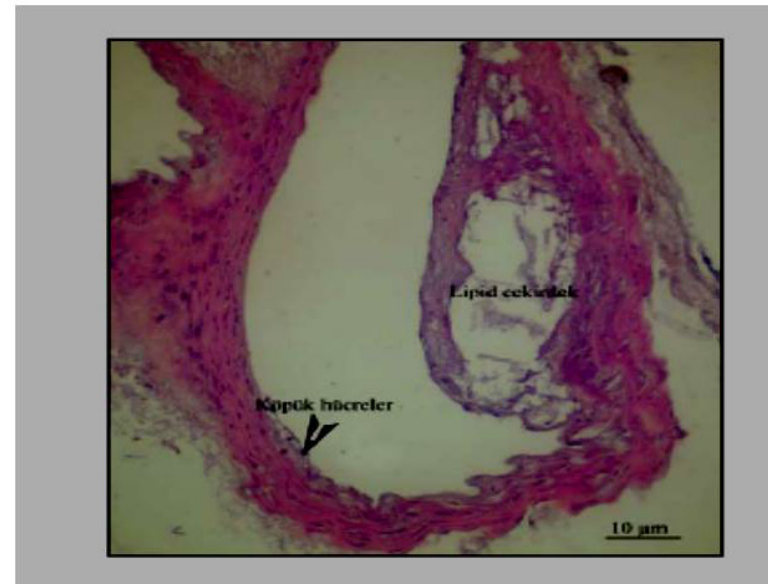

in IL-6 levels among 4 ApoE ${ }^{-/}$mice groups ( $\left.\mathrm{p}>0.05\right)$. Darbepoetin- $\alpha$ treatment decreased IL- 6 levels in $\mathrm{ApoE}^{-/-}$ mice groups at the initial and advanced atherosclerotic stages compared to the corresponding non-treated ApoE knockout mice groups at the initial and advanced atherosclerotic stages, but these decreases were not significant $(\mathrm{p}>0.05)$.

\section{Histamine level}

Histamine levels were significantly higher in $4 \mathrm{ApoE}^{-/-}$ mice groups compared to the $\mathrm{C} 57 \mathrm{BL} / 6$ mice group $(\mathrm{p}<0.05)$, as shown in Fig. 7. The highest level was found in the non-treated ApoE knockout mice group at the advanced atherosclerotic stage compared to the other 3 ApoE knockout mice groups, although these differences among $4 \mathrm{ApoE}^{-/-}$mice groups were not significant $(p>0.05)$. Darbepoetin- $\alpha$ treatment decreased histamine levels in $\mathrm{ApoE}^{-/-}$mice groups at the initial and advanced atherosclerotic stages compared to the corresponding non-treated $\mathrm{ApoE}^{-1-}$ mice groups at the initial and advanced atherosclerotic stages, but these decreases were not significant $(\mathrm{p}>0.05)$. 
Fig. 2. Triglyceride levels of the control (C57BL/6), IA (initial atherosclerotic $\mathrm{ApoE}^{-/-}$mice group treated with saline), IAD (initial atherosclerotic ApoE ${ }^{-/-}$ mice group treated with darbepoetin-a), AA (advanced atherosclerotic $\mathrm{ApoE}^{-/-}$mice group treated with saline) and AAD (advanced atherosclerotic $A p o E^{-/}$mice group treated with darbepoetin-a). Data is expressed as mean \pm standard deviation (SD)

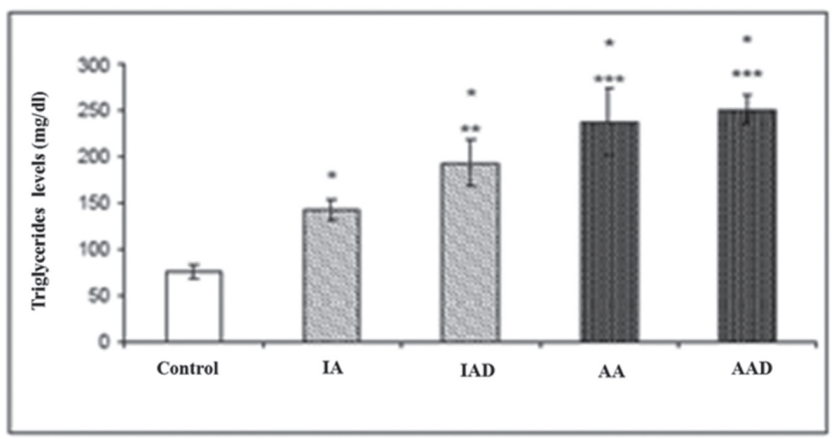

${ }^{*} p<0.001$, darbepoetin- $a$-treated and non-treated ApoE-/- mice groups at the initial and advanced atherosclerotic stages vs the control group; ${ }^{* *} p<0.05$, darbepoetin-a-treated vs. non-treated ApoE-/- mice groups at the initial atherosclerotic stage; ${ }^{* * *} p<0.05$, darbepoetin-a-treated and non-treated ApoE-/- mice groups at the advanced stage vs darbepoetina-treated and non-treated ApoE-/- mice groups at the initial stage.

Fig. 4. Serum carbonyl levels of the control (C57BL/6), IA, IAD, AA and AAD groups. Data is expressed as mean \pm standard deviation (SD)

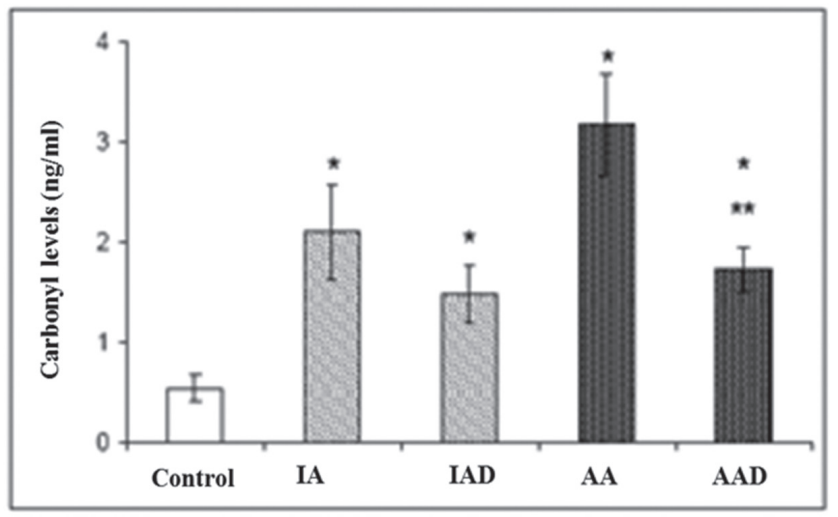

${ }^{*} p<0.001$, darbepoetin- $a$-treated and non-treated ApoE ${ }^{-/-}$mice groups at the initial and advanced atherosclerotic stages vs the control group; ${ }^{* *} \mathrm{p}<0.05$, darbepoetin-a-treated vs non-treated $\mathrm{ApoE}^{-/-}$mice groups at the advanced atherosclerotic stage.

Fig. 6. IL-6 level of the control (C57BL/6), IA, IAD, AA and AAD groups. Data is expressed as mean \pm standard deviation (SD)

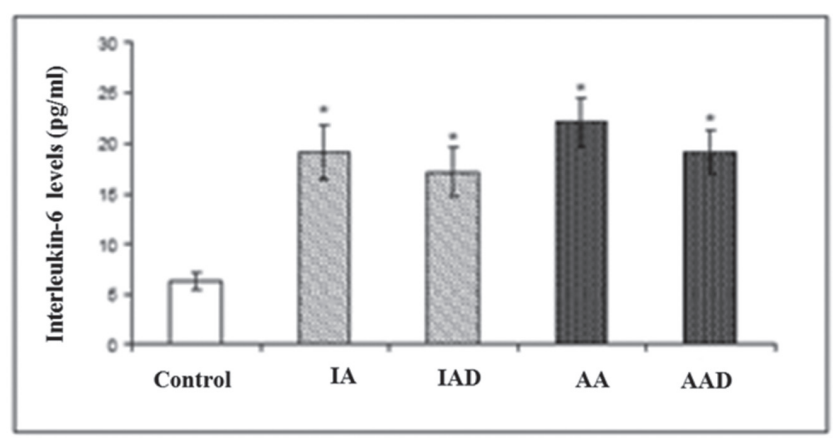

${ }^{*} p<0.001$, darbepoetin-a-treated and non-treated ApoE ${ }^{-/-}$mice groups at the initial and advanced atherosclerotic stages vs the control group.
Fig. 3. Cholesterol level of the control (C57BL/6), IA, IAD, AA and AAD groups. Data is expressed as mean \pm standard deviation (SD)

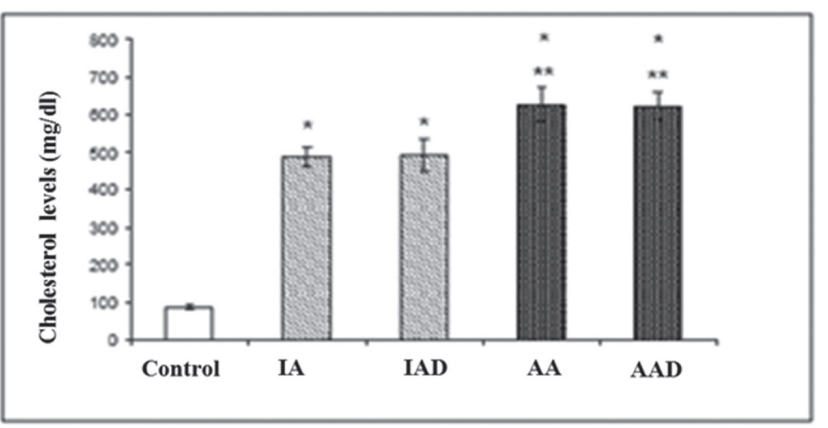

${ }^{*} \mathrm{p}<0.001$, darbepoetin- $\mathrm{a}$-treated and non-treated $\mathrm{ApoE}^{-/-}$mice groups at the initial and advanced atherosclerotic stages vs the control group; ${ }^{* *} p<0.05$, darbepoetin- $a$-treated and non-treated $\mathrm{Apo}^{-/-}$mice groups at the advanced stage vs darbepoetin-a-treated and non-treated ApoE ${ }^{-/}$ mice groups at the initial stage.

Fig. 5. 8-isoprostane levels of the control (C57BL/6), IA, IAD, AA and AAD groups. Data is expressed as mean \pm standard deviation (SD)

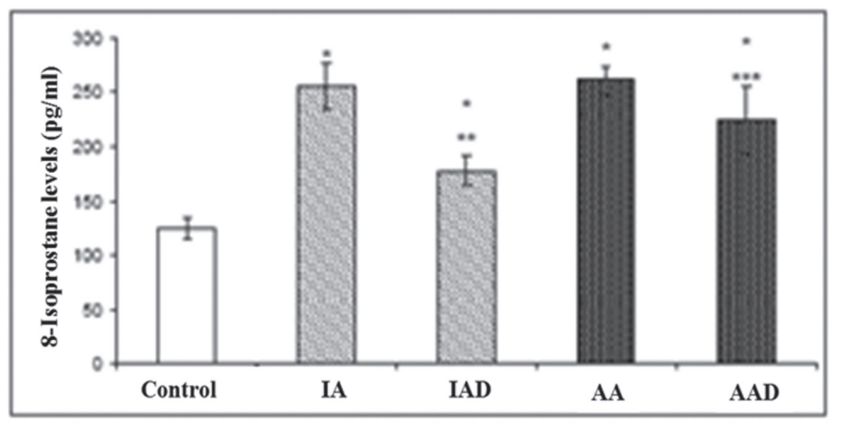

${ }^{*} p<0.001$, darbepoetin-a-treated and non-treated ApoE ${ }^{-/-}$mice groups at the initial and advanced atherosclerotic stages vs. the control group; ${ }^{* *} \mathrm{p}<0.01$, darbepoetin-a-treated vs non-treated $\mathrm{ApoE}^{-/}$mice groups at the initial atherosclerotic stage; ${ }^{* * *} \mathrm{p}<0.05$, darbepoetin-a-treated vs non-treated $\mathrm{ApoE}^{-/-}$mice groups at the advanced atherosclerotic stage.

\section{C-reactive protein (CRP) levels}

CRP levels were significantly higher in the four $\mathrm{ApoE}^{-/-}$ mice groups compared to the $\mathrm{C} 57 \mathrm{BL} / 6$ mice group $(\mathrm{p}<0.01)$, as shown in Fig. 8. CRP level was significantly higher in the non-treated ApoE knockout mice group at the advanced stage compared to the non-treated ApoE knockout mice group at the initial stage $(\mathrm{p}<0.01)$. Darbepoetin- $\alpha$ treatment decreased CRP levels in ApoE knockout mice groups at the initial and advanced atherosclerotic stages compared to the corresponding non-treated ApoE knockout mice groups at the initial and advanced atherosclerotic stages, but these decreases were not significant $(\mathrm{p}>0.05)$.

\section{E-selectin level}

The levels of E-selectin were markedly higher in $4 \mathrm{ApoE}^{-1-}$ mice groups compared to the $\mathrm{C} 57 \mathrm{BL} / 6$ mice group $(\mathrm{p}<0.01)$, as shown in Fig. 9. There was a non-significant increase in E-selectin level in the non-treated ApoE knockout mice group at the advanced stage compared to 
Fig. 7. Serum histamine level of the control (C57BL/6), IA, IAD, AA and AAD groups. Data is expressed as mean \pm standard deviation (SD)

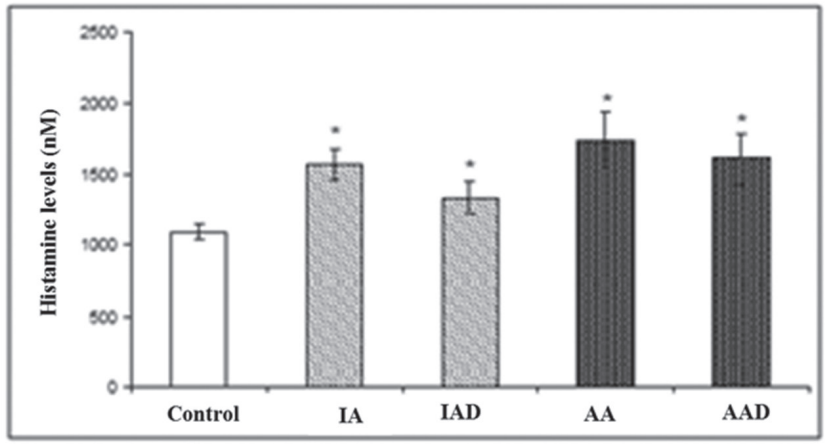

${ }^{*} \mathrm{p}<0.05$, darbepoetin-a-treated and non-treated $\mathrm{ApoE}^{-/-}$mice groups at the initial and advanced atherosclerotic stages vs the control group.

the non-treated ApoE knockout mice group at the initial stage ( $p>0.05$ ). Darbepoetin- $\alpha$ treatment nonsignificantly decreased the E-selectin level in $\mathrm{ApoE}^{-/-}$mice groups at the advanced atherosclerotic stage compared to the non-treated ApoE knockout mice group at the advance atherosclerotic stage.

\section{ICAM-1 (CD54) level}

Soluble intercellular cell adhesion molecule levels were significantly higher in $4 \mathrm{ApoE}^{-/-}$mice groups compared to the C57BL/6 mice group ( $\mathrm{p}<0.01$ ), as shown in Fig. 10. There was a marked increase in ICAM-1 level in the non-treated ApoE knockout mice group at the advanced stage compared to the non-treated $\mathrm{ApoE}^{-/-}$mice group at the initial stage $(\mathrm{p}<0.05)$. Darbepoetin- $\alpha$ treatment decreased ICAM-1 level in ApoE ${ }^{-/}$mice groups at the initial and advanced atherosclerotic stages compared to the corresponding non-treated ApoE knockout mice groups at the initial and advanced atherosclerotic stages, but these decreases were not significant $(\mathrm{p}>0.05)$.

\section{Discussion}

Our study explained the differences in various biochemical parameters regarding lipid profile, inflammation, endothelial injury and oxidative stress in $\mathrm{ApoE}^{-/-}$ mice receiving darbepoetin- $\alpha$ or saline and the effects of darbepoetin- $\alpha$ on the studied parameters. C57BL/6 mice, having the same genetic background except the ApoE gene served as the control group. ${ }^{14}$ Histological assessment of the atherosclerotic lesions to demonstrate overt signs of atherosclerotic changes, lipid accumulation, foam cell and plaque formation during atherosclerosis progression was carried out in the sections obtained from the aortic arch (arcus aortae) and subjected to immunohistochemical staining from the $\mathrm{ApoE}^{-/-}$mice at 8, 12 and 20 weeks of age. From the initial to advanced stage of atherosclerosis, the median value of the aorta lumen was
Fig. 8. CRP level of the control (C57BL/6), IA, IAD, AA and AAD groups. Data is expressed as mean \pm standard deviation (SD)

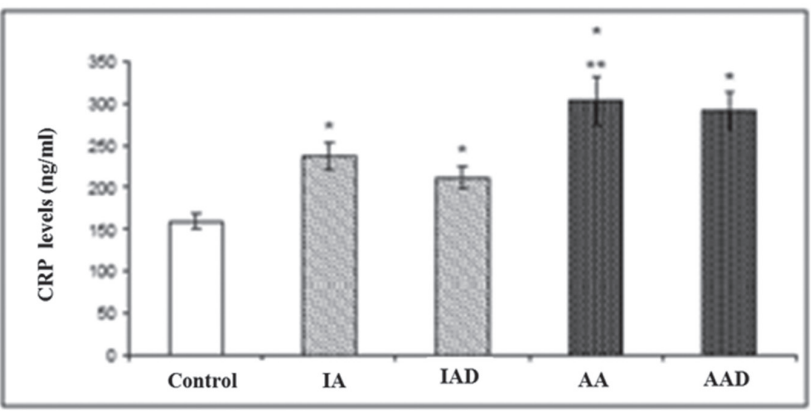

${ }^{*} p<0.01$, darbepoetin-a-treated and non-treated ApoE ${ }^{-/-}$mice groups at the initial and advanced atherosclerotic stages vs the control group; ${ }^{* *} \mathrm{p}<0.01$, Non-treated ApoE ${ }^{-/-}$mice group at the advanced stage vs nontreated $\mathrm{ApoE}^{-/-}$mice group at the initial stage.

Fig. 9. Serum E-selectin level of the control (C57BL/6), IA, IAD, AA and AAD groups. Data is expressed as mean \pm standard deviation (SD)

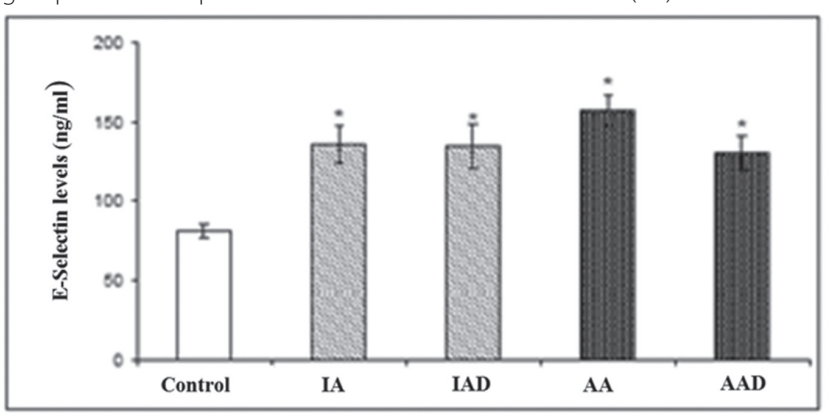

* $p<0.01$, darbepoetin-a-treated and non-treated ApoE ${ }^{-/-}$mice groups at the initial and advanced atherosclerotic stages vs the control group.

Fig. 10. sICAM-1 level of the control (C57BL/6), IA, IAD, AA and AAD groups. Data is expressed as mean \pm standard deviation (SD)

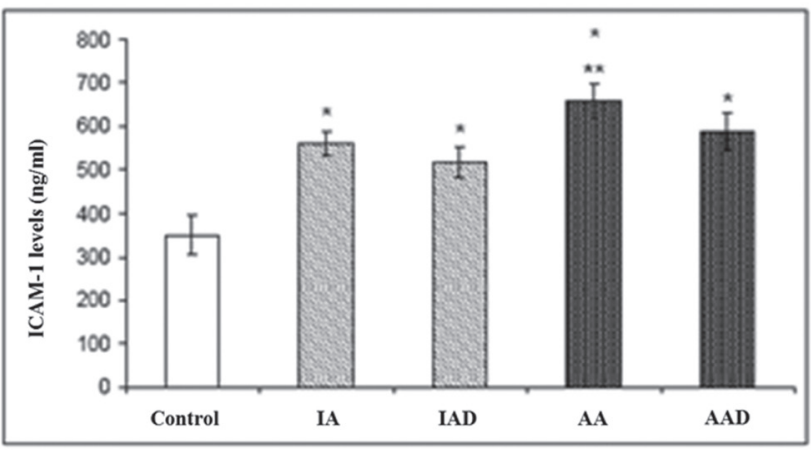

${ }^{*} p<0.01$, darbepoetin-a-treated and non-treated $\mathrm{ApoE}^{-/-}$mice groups at the initial and advanced atherosclerotic stages vs the control group; ${ }^{* *} \mathrm{p}<0.05$, non-treated ApoE $\mathrm{E}^{-/}$mice group at the advanced stage vs nontreated $\mathrm{ApoE}^{-/-}$mice group at the initial stage.

diminished, indicating narrowing of the lumen gradually. Atherosclerotic lesion development was first seen at the age of 8 weeks in the ApoE $\mathrm{E}^{-/-}$mice. At the $20^{\text {th }}$ week of age, ApoE knockout mice developed foam cells in the aortic arch. Our observations are in accordance with the studies of Jawien et al., who reported that the ApoE knockout mice model is the only one that develops large-scale accelerated atherosclerotic lesions. ${ }^{17}$ 
Apolipoprotein E gene mutations increase cholesterol and triglyceride levels leading to accelerated atherosclerosis. ${ }^{18}$ In fact, the $\mathrm{ApoE}^{-/-}$mice used in our study had hypercholesterolemia and hypertriglyceridemia and developed accelerated atherosclerosis. ${ }^{9}$ The increases in triglyceride and cholesterol levels were in parallel with the stages of atherosclerosis in the ApoE knockout mice. We evaluated the short and long term responses of darbepoetin- $\alpha$ on the characteristics of atherosclerosis in $\mathrm{ApoE}^{-/-}$mice. Darbepoetin- $\alpha$ treatment significantly increased triglyceride and cholesterol levels compared to the saline-treated $\mathrm{ApoE}^{-/-}$mice groups at the initial and advanced stages of atherosclerosis.

We determined oxidative stress parameters such as 8-isoprostane as a lipid peroxidation index and protein carbonyl as a protein oxidation index in the control and ApoE ${ }^{-/-}$mice groups. 8-isoprostane and protein carbonyl levels were significantly increased in the $\mathrm{ApoE}^{-/-}$mice groups compared to the $\mathrm{C} 57 \mathrm{BL} / 6$ mice group, indicating an increase in oxidative stress during atherosclerosis development. Darbepoetin- $\alpha$ treatment significantly lowered enhanced oxidative stress marker levels in the ApoE knockout mice in comparison to the saline-injected $\mathrm{ApoE}^{-/-}$mice. The decreases in 8-isoprostane levels by darbepoetin- $\alpha$ treatment were significant in the $\mathrm{ApoE}^{-/-}$ mice groups at the initial and advanced atherosclerotic stages, but the decreases in protein carbonyl levels were significant in the Apo: $\mathrm{E}^{-/-}$mice group only at the advanced atherosclerotic stage compared to the corresponding non-treated ApoE knockout mice groups at the initial and advanced atherosclerotic stages. Our findings of diminishing oxidative stress markers in $\mathrm{ApoE}^{-/-}$mice receiving darbepoetin- $\alpha$ at the initial or advanced atherosclerotic stages, when compared to the corresponding non-treated ApoE $E^{-/-}$mice groups, indicate the antioxidative effects of darbepoetin- $\alpha$.

Although long term darbepoetin- $\alpha$ treatment reduced oxidative stress parameters in ApoE knockout mice, and it did not change the markers of lipid profile (compared to the untreated, advanced atherosclerotic group) and endothelial injury, similar to the reports by Monostori et al. and Parissis et al. ${ }^{19,20}$ Increased plasma protein carbonyls in patients with hypercholesterolemia have been reported, indicating that the plasma protein carbonyl is a sensitive index of oxidative stress..$^{20,21}$

Our findings showed that IL-6 and CRP levels, well known inflammation markers, were raised in parallel with the stage of atherosclerosis in the non-darbepoetin- $\alpha$-treated ApoE knockout mice group. ${ }^{22}$ Darbepoetin- $\alpha$ treatment decreased these inflammation markers in the $\mathrm{ApoE}^{-/-}$mice both at the advanced and initial atherosclerosis stages. Related to our findings, Wilund et al. published that IL- 6 and CRP were enhanced in ApoE knockout mice compared to ApoE ${ }^{+/+}$mice. ${ }^{23}$ In accordance with our findings, Arend et al. reported a significant decrease in CRP expression in darbepoetin- $\alpha$-treated
ApoE $^{-/-}$mice. ${ }^{24}$ In a study performed by Huang et al. it was reported that basal serum IL- 6 levels of ApoE knockout mice were akin to those in C57BL mice. ${ }^{25}$

Histamine and its receptors are formed in atherosclerotic lesions, and their signaling and following proinflammatory and proatherogenic gene expression are involved in the progress of atherogenesis. Wang et al. showed that histamine was associated with the development of atherosclerosis in ApoE knockout mice by regulating the gene expression of inflammatory modulators independent of serum cholesterol levels. In addition, histamine participates in hyperlipidemia-induced atherosclerosis. ${ }^{26}$ Huang et al. reported that serum histamine in ApoE knockout mice was markedly increased compared to the level in control (C57BL) mice. ${ }^{27}$ Serum histamine, CRP and IL-6 levels were shown to be increased in acute coronary syndrome and stable coronary artery disease. ${ }^{28}$ In our study, darbepoetin- $\alpha$ treatment decreased histamine levels in Apo: ${ }^{-1-}$ mice groups at the initial and advanced atherosclerotic stages compared to the corresponding non-treated $\mathrm{ApoE}^{-/-}$mice, although these decreases were not statistically significant. E-selectin, IL- 6 and histamine levels were not affected significantly by darbepoetin- $\alpha$ administration between $\mathrm{ApoE}^{-/-}$mice groups at both initial and advanced stages.

During the progression of atherosclerosis from the initial stage to the advanced stage, elevated E-selectin and ICAM-1 levels were observed in the non-treated $\mathrm{ApoE}^{-/-}$ mice. We found increased E-selectin and ICAM-1 levels as indicators of endothelial injury in the non-treated ApoE knockout mice group at the advanced stage of atherosclerosis compared to the non-treated ApoE knockout mice group at the initial stage, but only the increase in ICAM-1 level was significant. Elevated ICAM-1 levels in $\mathrm{ApoE}^{-/-}$mice were also reported by Liyama et al. ${ }^{29} \mathrm{Ru}-$ bio-Guerra et al. found a significant correlation between maximal carotid artery intimal-medial thickness and ICAM-1 levels, whereas correlation was not observed with E-selectin in patients with diabetes-associated atherosclerosis. ${ }^{30}$ In our study, darbepoetin treatment led to a non-significant decrease in ICAM-1 level in the ApoE ${ }^{-/-}$ mice group compared to the corresponding non-darbepoetin- $\alpha$ treated $\mathrm{ApoE}^{-/-}$mice at both initial and advanced atherosclerosis stages. Arend et al. reported that ICAM protein expression in the aorta did not differ markedly between the nephrectomized or darbepoetin- $\alpha$-treated groups, neither in the intramyocardial arteries and aortic plaque nor in the aortic endothelium of $\mathrm{ApoE}^{-/-}$mice. ${ }^{24}$

Endothelial function is impaired in the earlier stages of atherogenesis and is strongly correlated with several risk factors. Endothelial dysfunction predisposes to longterm atherosclerotic lesions and has been proposed as an important diagnostic and prognostic factor. The production of oxidative reactive radicals induces dysfunction of the endothelium, the first step of atherogenesis. In such studies, the specificity of the preferred parameters for the 
definition of atherosclerosis needs to be tested in specimens. "The biochemical analyses revealed that several parameters in serum might be involved in the development and/or progression of atherosclerosis in $\mathrm{ApoE}^{-/-}$mice and these parameters could be affected by the darbepoetin- $\alpha$ treatment". ${ }^{16}$

In our study, we compared the selected markers of lipid profile, inflammation, endothelial injury and oxidative stress in atherosclerotic ApoE knockout mice treated or non-treated with darbepoetin- $\alpha$. We revealed that long term darbepoetin- $\alpha$ treatment reduced oxidative stress and inflammation in $\mathrm{ApoE}^{-/-}$mice, but did not influence lipid profile (compared to the untreated advanced atherosclerotic group) and endothelial injury significantly. Our study demonstrated the efficacy of darbepoetin- $\alpha$ in reducing CRP and protein carbonyl levels in ApoEknockout mice during atherosclerosis progression. We conclude that darbepoetin- $\alpha$ is efficient in reducing inflammation and oxidative stress, which are potent inducers of atherosclerosis in $\mathrm{ApoE}^{-/-}$mice.

\section{References}

1. Anderson TJ. Assessment and treatment of endothelial dysfunction in humans. J Am Coll Cardiol. 1993;4:631-638.

2. Pyorala K, Laakso M, Uusitupa M. Diabetes and atherosclerosis: An epidemiologic view. Diabetes Metab Rev. 1987;3:463-524.

3. Thomas MC, Pickering RJ, Tsorotes D, et al. Genetic Ace2 deficiency accentuates vascular inflammation and atherosclerosis in the ApoE knockout mouse. Circ Res. 2010;10:888-897.

4. Stylianou IM, Bauer RC, Reilly MP, Rader DJ. Genetic basis of atherosclerosis: Insights from mice and humans. Circ Res. 2012;110: 337-355.

5. Coleman LS. Atherosclerosis may be caused by inadequate levels of turbulence and mixing. World J Surg. 2006;30:638-639.

6. Nakashima Y, Plump AS, Raines EW, Breslow JL, Ross R. ApoE-deficient mice develop lesions of all phases of atherosclerosis throughout the arterial tree. Arterioscler Thromb. 1994;14:133-140.

7. Aviram M, Volkova N, Coleman R, et al. Pomegranate phenolics from the peels, arils, and flowers are antiatherogenic: Studies in vivo in atherosclerotic apolipoprotein e-deficient $(E 0)$ mice and in vitro in cultured macrophages and lipoproteins. J Agric Food Chem. 2008;56:1148-1157.

8. Rosenblat M, Volkova N, Coleman R, Almagor Y, Aviram M. Antiatherogenicity of extra virgin olive oil and its enrichment with green tea polyphenols in the atherosclerotic apolipoprotein-E-deficient mice: enhanced macrophage cholesterol efflux. J Nutr Biochem. 2008;19:514-523.

9. Plump AS, Smith JD, Hayek T, et al. Severe hypercholesterolemia and atherosclerosis in apolipoprotein E-deficient mice created by homologous recombination in ES cells. Cell. 1997;71:343-353.

10. Johnson DW, Pat B, Vesey DA, Guan Z, Endre Z, Gobe GC. Delayed administration of darbepoetin or erythropoietin protects against ischemic acute renal injury and failure. Kidney Int. 2006;69: 1806-1813.

11. Esquerdo G, Domenech M, Lopez P, et al. Darbepoetin alfa administered once every three weeks for the treatment of anemia in elderly patients with non-myeloid tumors receiving chemotherapy. Tumori. 2014;100:225-231.

12. Le Minh K, Klemm K, Abshagen K, Eipel C, Menger MD, Vollmar B. Attenuation of inflammation and apoptosis by pre- and posttreatment of darbepoetin-alpha in acute liver failure of mice. Am J Pathol. 2007;170:1954-1963.
13. Gao E, Boucher M, Chuprun JK, Zhou RH, Eckhart AD, Koch WJ. Darbepoetin alfa, a long-acting erythropoietin analog, offers novel and delayed cardioprotection for the ischemic heart. Am J Physiol Heart Circ Physiol. 2007;29:60-68.

14. Dursun E, Ozben B, Monari E, Cuoghi A, Tomasi A, Ozben T. Proteomic profiling in apolipoprotein E-deficient mice during atherosclerosis progression. Acta Histochem. 2010;112:178-188.

15. Dursun E, Monari E, Cuoghi A, et al. Proteomic profiling during atherosclerosis progression using SELDI-TOF-MS: Effect of darbepoetin treatment. Acta Histochem. 2010;112:432-443.

16. Ozben B, Dursun E, Monari E, et al. Proteomic profiling during atherosclerosis progression: Effect of nebivolol treatment. Mol Cell Biochem. 2009;331:9-17.

17. Jawien J, Nastalek P, Korbut R. Mouse models of experimental atherosclerosis. J Physiol Pharmacol. 2004;55:503-517.

18. Solanas-Barca M, de Castro-Oros I, Mateo-Gallego R, et al. Apolipoprotein $\mathrm{E}$ gene mutations in subjects with mixed hyperlipidemia and a clinical diagnosis of familial combined hyperlipidemia. Atherosclerosis. 2012;222:449-455.

19. Monostori P, Hracsko Z, Karg E, et al. Erythropoiesis-stimulating agent withdrawal and oxidative stress in hemodialysis. Clin Nephrol. 2009;71:521-526.

20. Parissis JT, Kourea K, Andreadou I, et al. Effects of darbepoetin alfa on plasma mediators of oxidative and nitrosative stress in anemic patients with chronic heart failure secondary to ischemic or idiopathic dilated cardiomyopathy. Am J Cardiol. 2009;103:1134-1138.

21. Pirinccioglu AG, Gokalp D, Pirinccioglu M, Kizil G, Kizil M. Malondialdehyde (MDA) and protein carbonyl (PCO) levels as biomarkers of oxidative stress in subjects with familial hypercholesterolemia. Clin Biochem. 2010;43:1220-1224.

22. Sukovich DA, Kauser K, Shirley FD, DelVecchio V, Halks-Miller M, Rubanyi GM. Expression of interleukin- 6 in atherosclerotic lesions of male ApoE-knockout mice: Inhibition by 17beta-estradiol. Arterioscler Thromb Vasc Biol. 1998;18:1498-1505.

23. Wilund KR, Rosenblat M, Chung HR, et al. Macrophages from alpha 7 nicotinic acetylcholine receptor knockout mice demonstrate increased cholesterol accumulation and decreased cellular paraoxonase expression: A possible link between the nervous system and atherosclerosis development. Biochem Biophys Res Commun. 2009;390:148-154.

24. Arend N, Hilgers KF, Campean V, et al. Darbepoetin alpha reduces oxidative stress and chronic inflammation in atherosclerotic lesions of apo $\mathrm{E}$ deficient mice in experimental renal failure. PLoS One. 2014;9:e88601.

25. Huang M, Pang X, Karalis K, Theoharides TC. Stress-induced interleukin- 6 release in mice is mast cell-dependent and more pronounced in Apolipoprotein E knockout mice. Cardiovasc Res. 2003;59:241-249.

26. Wang KY, Tanimoto A, Guo X, et al. Histamine deficiency decreases atherosclerosis and inflammatory response in apolipoprotein $\mathrm{E}$ knockout mice independently of serum cholesterol level. Arterioscler Thromb Vasc Biol. 2011;31:800-807.

27. Huang M, Pang X, Letourneau R, Boucher W, Theoharides TC. Acute stress induces cardiac mast cell activation and histamine release, effects that are increased in apolipoprotein E knockout mice. Cardiovasc Res. 2002:55:150-160.

28. Clejan S, Japa S, Clemetson C, Hasabnis SS, David O, Talano JV. Blood histamine is associated with coronary artery disease, cardiac events and severity of inflammation and atherosclerosis. J Cell Mol Med. 2002;6:583-592.

29. liyama K, Hajra L, liyama M, et al. Patterns of vascular cell adhesion molecule-1 and intercellular adhesion molecule-1 expression in rabbit and mouse atherosclerotic lesions and at sites predisposed to lesion formation. Circ Res. 1999;85:199-207.

30. Rubio-Guerra AF, Vargas-Robles $\mathrm{H}$, Lozano Nuevo JJ, EscalanteAcosta BA. Correlation between circulating adhesion molecule levels and albuminuria in type-2 diabetic hypertensive patients. Kidney Blood Press Res. 2009;32:106-109. 